\title{
A New Perspective on Job Characteristic Model: Task Design and Working Incentive of Expatriate Managers Under the Belt \& Road Initiative
}

\author{
Yuran Li \\ International Business School \\ Yunnan University of Finance and \\ Economics \\ Kunming, China \\ biwoo@foxmail.com
}

\author{
Ying Zhang* \\ 1. School of Management and \\ Marketing \\ Charles Sturt University \\ Wagga Wagga, Australia \\ 2. International Business School \\ Yunnan University of Finance and \\ Economics \\ Kunming, China \\ angie@ynufe.edu.cn
}

\author{
Puzhen Xiong \\ International Business School \\ Yunnan University of Finance \& \\ Economics \\ Kunming, China \\ 584682089@qq.com
}

\begin{abstract}
The Belt \& Road Initiative brings out new conceptualization for the ability and competency of expatriate managers, the role of whom are of great significance to the development and operations of subsidiaries from multinational corporations. Due to the lack of effective training and incentive measures for expatriate managers, the conflicts between institutional and expatriate managers become increasingly severe. This paper analyses the specific dimensions of the work characteristic model and its influence on the job morale, job attitude, job behavior and job performance from expatriate managers. Through observing the relationship between task design and job performance, we can better understand the conflicts happened between institution and expatriate managers. It is proposed that the task design of expatriate managers, which is based on the job characteristic model, is positively related to their job behavior and performance.
\end{abstract}

Keywords: expatriate manager, job characteristic model, task design, incentive

\section{INTRODUCTION}

Appealing to the call of construction of a community with shared future for mankind, the One Belt \& One Road (OBOR) came into being. The Belt \& Road Initiative brings loads of opportunities for development and the potentiality emerged in diverse industries. The expatriate manager, defined as the direct management of institutions in multinational corporations overseas, their ability of management, consciousness of innovation, sense of responsibility, and enthusiasm of work are of great importance to the efficiency and direct cost of institutions. This paper mainly discusses about how the relationship between the task design and job morale of expatriate managers influence their job performance and how conflicts happen when they are unsatisfied with their leaders and management system.

The work characteristic model of Hackman and Oldham (1976) [1] argues that the core dimension of job characteristic includes the integrity and importance of task, the diversity of skills, the autonomy, and the feedback of task. According to the model, a single task affects the psychological feelings of employees from three aspects-the feeling of meaning and value of their work, the feeling of link between themselves and the completeness of their work, and the feeling of the mastery of progress and performance evaluation of their work. And Robbins et al (2008) [2] define the task design of job as a series of management activities, which is used to determine the scope, responsibility, and work relations of work activities for the stuff. It is also a process of demarcation for the way to complete the work, and the required specific behavior to accomplish the task. As for incentive theory, it mainly refers to content-based incentive theory, which emphasizes on the stimulus of incentives. It generally consists of Maslow's demand theory, Hertzberg's encouragement-health care double factor theory, McClelland's achievement-demand incentive theory, and Oldford's ERG theory, etc.

\section{LITERATURE REVIEW}

In the following parts, we firstly review the job characteristic model (JCM), JCM has six dimensions which includes: the diversity of skills, the integrity of job, the importance of job, the autonomy of job, and the feedback of job. Secondly, we review the project team management

*Corresponding author 
research, the emphasis of research on project team management varies home and abroad. And the project team management influence the success of the project. Thirdly, we review the task design, which identifies three aspect of ability for expatriate managers. Finally, we review the incentive theory, there are four main theories which includes: Maslow's hierarchy of needs theory, Herzberg's incentive-health care theory, control incentive theory, and flexible incentive mechanism. Through the reviewing of four concepts, we can better comprehend the factors that influence the performance of expatriate managers.

\section{A. Job Characteristic Model (JCM)}

Job Characteristic Model (JCM), proposed by Hackman and Lawer (1971) [3], is one of the six mature methods of work design. Hackman and Oldham (1971) argue that the main job characteristics include six dimensions: integrity, diversity, autonomy, cooperation, feedback and friendship opportunities. In 1975, they replaced friendship opportunities with the importance of the task. And the same year, they developed the Job Diagnostic Survey (JDS) to verify the validity of the model. Later, Hackman et al (1975) [4] further developed the theory, they remove the "cooperative" factors and put forward two different feedback, that is, work feedback and others' feedback. Based on the previous research, finally, Hackman and his collaborators put forward the theory which argues that: the task design itself should include some basic characteristics, which can stimulate the work motivation of the staff. On the basis of summarizing the previous research, Hackman put forward the five core job characteristics and the conceptual framework of the interaction between the working characteristic and individual differences. Currently, it is the most famous and influential pattern of work design.

As the core element of job characteristic model, the diversity of skills refers to the required techniques and professional capabilities of an employee to complete a task. Considering the integrity, the integrity of job relates to the extent to which the job needs to be done as a whole - from the beginning of the work to the completion and the achievement of the obvious results. The importance of job refers to the the extent to which the staff affects the work or life of other people - whether within the organization or outside the working environment. The autonomy of job relates to the range of rights for individuals to complete specific task independently and freely. And the feedback of job refers to the evaluation of job performance and efficiency that an individual can get from leaders and others.

The Job Diagnostic Survey (JDS), developed by Hackman and Oldham (1975), is the most frequently used tool to measure the validity of five core job characteristics. It can calculate the extent of potential incentive with quantified scores, that is, motivating potential score (MPS), which represents the degree of job enrichment. Its calculation formula: MPS $=$ (job skill diversity + job integrity + job importance $) \div 3$ $\times$ job autonomy $\times$ job feedback. Currently, many other scholars' research about job characteristic are based on their job diagnostic survey.

\section{B. Project Team Management}

Many research lay great emphasis on the importance of project team management (e.g. Belout et al., 2004; Eskerod et al., 2005; Bakker et al., 2004). Project human resource management is one of the nine contents of management. Belout, Gauvreau (2004) [5] propose that the management of project human resources is an important factor that affects the success of the project, and a high-efficient project team requires a clear definition of responsibilities and rights of each person. Eskerod, Blichfeldt (2005) [6] and Zwikael, UngerAviram (2010) [7] argue that the project team plays a different role in the different stages of the project cycle, and the team need to adjust the approach of management accompanied with the cycle of each specific project. Bakker et al (2004) [8] suggest that the human resource management of project teams varies according to different project management environment In the case where the project is simple, the team structure is stable and the project management mode is more traditional, it is necessary to carry out a series of management measures with strong sustainability to each independent member; while under the circumstances where the project is more complicated, with more uncertainty and obstacles, then a more diversified and flexible measure of team management is required.

Meanwhile, some research pay attention to the "individual-level" aspect of team management (e.g. Wan, 2014; Wu et al., 2010; Zhang, 2014). Wan (2014) [9] believed that the single "person" is of great importance to the successful accomplishment of a project. To accomplish a whole project, the project team need to conduct scientific management and strengthen the team personnel communication on task. Meanwhile, Wu et al (2010) [10] advocated the construction of the project team in order to create a harmonious and positive working atmosphere to help team members growing simultaneously, which can better improve the efficiency of project management. There are also some research focus on approaches and incentive mechanism of expatriate managers' team management. Sun (2012) [11] put forward the principle of maintaining fair rights and responsibilities, creating opportunities to cultivate talents through appropriate authorization. Within the organization, it is necessary for leaders to make use of personal leadership qualities to build prestige, so as to better facilitate people from all levels making concerted efforts to promote the project. Cao and Yang (2010) [12] proposed the designated methods of key performance indicators (KPI) and feedback mechanism of performance; Zhang (2014) [13] raised the use of 360-degree method to realize the all-round assessment of expatriate manager's performance. The approach provides motivation for continuous work with different incentive mechanism according to different traits appeared in different stages of projects. Guo (2002) [14] argues that the knowledge-based organization entails effective management of intellectual resources, in order to promote continuous progress and improve the comprehensive effectiveness of management for the organization. 


\section{Task Design}

The task design refers to the process that identifies the working scope of each team members, bears the relevant responsibilities, and specifies the standard should meet for the accomplishment of work. The rationality of task design frequently impacts the intuitive feelings of staff, and results in the difference in working behavior and performance. The task design theory goes through various stages of development,it originates in the advocation of specialization, which is from Taylor's management theory, he stressed the profession of work and efficiency of labour, so as to enhance the level of incentive. Then the advocation of job rotation appears, and further put forward the enrichment of job content and team cooperation. Custer and Rosenzweig (2000) [15] proved that the substitutability of the work is an important factor that impact the accomplishment of different task for expatriate managers; Zhang et al (2005) [16] suggests that diversified job design promotes the complementation of information between different tasks and further improves work efficiency; Dixit (2002) [17] analyze the problems of work incentive under multitasking situations; most of the above studies focus on the analysis of the impact of task design on incentives, but few focus on the quantitative evaluation of task design itself.

\section{Incentive Theory}

The incentive theory studies the impact of external stimuli on people's cognition. The law of human cognition, psychology and behavior, stimulate and mobilize people to actively engage in a task. And there are four main incentive theories: demand level theory, Herzberg's incentive-health care theory, control incentive theory, and flexible incentive mechanism.

\section{1) Hierarchy of Needs Theory}

Maslow (1970) [18] divides the demand of the people from low to high into seven levels: psychological demand, security demand, social demand, respect demand, knowledge demand, beauty demand, and self-realization demand. The satisfaction of a lower level of demand will lead to the pursuit of a higher level of demand, and individual believes that the higher-level demand is more valuable than the lower ones. The structure of human demand is dynamic, developing and changing. Therefore, it is more stable and lasting to satisfy the high-level demand of workers so as to mobilize their enthusiasm for production. Later, Alderfer et al (1973) [19] revised and restructured the original seven demand levels into three aspects: the existence demand, the relation demand, and growth demand (ERG). The ERG theory argues that existence, relations and demand, any of the three demand is indispensable. People who are lack of a kind of demand would be confused about the existing conditions. Furthermore, people who are at the highest level of demand would desire to strengthen their existing conditions of demand and so as to enjoy the satisfaction of growing demand. Hence, managers can enrich the measures of incentive according to different levels of demand for different people.

\section{2) Herzberg's Incentive-Health Care Theory}

American behavior scientist Frederick Herzberg proposed the "Two-Factor Theory". It argues that "incentives" are those factors that can bring positive attitudes, satisfaction and inspiration which can satisfy individual self-achievement, including: achievement, appreciation, challenging work, job responsibilities, and opportunities for growth and development. Those incentive factors would bring better performance of workers when applied appropriately during the management of staff.

\section{3) Control Incentive Theory}

$\mathrm{Xu}$ (2012) [20] pointed out that the granting of authority to the high-level personnel can be regarded as an incentive mechanism. Its essence includes: whether to grant specific control, the degree of control, and the corresponding return concerning the contribution. Therefore, the effectiveness of the control incentive depends on the symmetry between the extent of contribution and acquired power of control for the high-positioned worker in the company. As a more secret way of incentive, the control incentive derives from the fiercecompeted market environment and is widely used by managers in many companies. Furthermore, the relationship between technological innovation and control incentive is Ushaped, to the effect that, the increase in control incentive can stimulate the function of innovative ability when the control incentive was not at its peak; on the contrary, the control incentive would negatively impact innovative ability and further inhibit the exertion of technological innovation ability after its reaching of peak.

\section{4) Flexible Incentive Mechanism}

The flexible incentive is one of the reformation of traditional incentive mechanism. It is highly valued by the modern human resources management. Based on the research of psychological and behavioral law of company members, it is characteristic of the adoption of humanized method of management. By the use of non-compulsory measures, the flexible incentive imperceptibly change organizational intention into individual conscious action. The flexible incentive mechanism aims to find balance between humanization and institutionalization of management, in order to achieve the optimal state of management performance. The incentive mechanism includes goals behavior, honor, trust and etc.. The more flexible the incentive mechanism, the more obvious the incentive effect act on the staff, and consequently raising a higher enthusiasm to work. Liu and $\mathrm{Hu}$ (2010) [21] pointed out that the flexible incentive mechanism is a very effective strategy and method. The organization should deeply analyze the differences of workers ranging from their age, experience and to characteristics, in order to adopt targeted and differentiated ways of incentive. 


\section{THEORY DEVELOPMENT}

\section{A. Job Characteristic Model and Incentives}

According to the theory of job characteristics model, the five core characteristics of the task have different impact on psychological state of employees, thus affecting the employee's work behavior and extent of accomplishment of task performance.

\section{1) Job Skill Diversity}

The diversity of job skills refers to am exertion of various necessary working skills and problem-solving skills during the process of expatriate managers' task completion. The diversity of working skills stimulate the interest for accomplishing management task and avoiding the tiredness of work. The more obvious the trait of job diversity skills, the higher working mood and contribution to work of expatriate managers will raise. Therefore, this paper postulates that:

P1: The job skill diversity will be positively related to the incentives.

\section{2) Job Integrity}

The integrity of job refers to the complete working procedure ranging from the engagement and participation of a specific task, and the promotion of the process, to the access to the share of working results. The integrity of job arouse the sense of responsibility and security for the expatriate managers to the work, which entails more attention and concern. With the integrity of job, expatriate managers are not just repeat their single and boring work infinitely, but participating into the process of witnessing and sharing the results of concerted efforts. The more integrity of job, the better effect of incentive. Thus, it can be expected that:

P2: The job integrity will be positively related to the incentives.

\section{3) Job Importance}

The job importance, as the name implies, is the value of a task. The accomplishment of a task has an important impact on the members, department, and the organization. The more important the task is, the greater impact it has, and the more value it holds. When expatriate managers consider their job of high significance and importance to the company, and their role are recognized, they will have more sense of mission and responsibility, which results in a higher working mood and stimulates more working incentives. Therefore, we suggest that:

P3: The job importance will be positively related to the incentives.

\section{4) Job Autonomy}

The job autonomy refers to the staff's own methods, measures, and time-arrangements of accomplishing a specific task according to correlated conditions. For the expatriate managers with average-level of comprehensive quality and ability, the detailed division of task and clarified contents and rules of work would benefit them with clear job responsibilities. Nevertheless, for the expatriate managers with high-level of comprehensive quality and ability, if the work is divided into too small modules and required to be done step by step with strict rules, it's difficult for them to give their subjective initiatives into full play, and establish their confidence in work, which consequently strikes their working mood and performance. Hence, it's necessary to release more space for expatriate managers with higher comprehensive ability and quality, to have more freedom on selfdetermination, so as to improve the degree of autonomy and arouse more incentives for job. Therefore, we intend that:

P4: The job autonomy will be positively related to the incentives.

\section{5) Job Feedback}

The job feedback refers to the accurate information about self-evaluation on the accomplishment of task that staff can acquired. With feedback, expatriate managers can have a timely mastery of working results, make clear of the working procedure, and know their effectiveness of work, so as to frequently correct their own working behavior. Through feedback from different leaders, expatriate managers can perceive their concerns for work and the degree of recognition. After the correction of imperfections and targeted improvement in working skills, expatriate managers will strengthen their confidence in work and further have incentives to improve their job performance and effectiveness. Hence, it is prostituted that:

P5: The job feedback will be positively related to the incentives.

\section{B. Task Design and Incentives}

The task design refers to the process that identifies the working scope of each team members, bears the relevant responsibilities, and specifies the standard should meet for the accomplishment of work. The rationality of task design frequently impacts the intuitive feelings of staff, and results in the difference in working behavior and performance. A wellmanaged task design will finely arrange the specification of different task for expatriate managers, to better acknowledge the division of work and impact the behavior and performance of staff. With a good task design, expatriate managers will have motivation to take responsibility for their performance and keep enthusiasm for job, consequently, have more incentives to perform well. Therefore, we expect that:

P6: The task design will be positively related to the incentives.

\section{DISCUSSION AND CONCLUSIONS}

Under the back ground of The Belt and Road initiative, which not only provides a platform for expatriate managers 
from different companies to gather together and communicate with each other, but also facilitates expatriate managers to broaden their horizon and absorb more open and significant perceptions through out the world. To reduce the possibility of failing management and promote more effective and successful methods of job behavior and performance, future research should pay more attention to the area. Since it will lower the cost of multinational companies for targeted and specific training and selection.

Based on the incentive theory, which contains four main theories: the hierarchy of needs theory, Herzberg's incentivehealth care theory, the control incentive theory, and the flexible incentive mechanism, additionally, the theory of job characteristic model, especially for its five dimensions, and the theory of task design, this paper mainly discusses the impact mechanism of five dimensions of job characteristic model, that is, job skills diversity, job integrity, job importance, job autonomy, and job feedback on the expatriate managers' working incentives. The propositions of this paper suggest that the five dimensions of job characteristic model and the task design will be positively related to the expatriate managers' working incentives. The study assumes that those jobs which are abundant of skills diversity, integrity, importance, autonomy, and feedback are stimulation for the expatriate managers' incentives, and a better-organized task design will raise the sense of mission and responsibility for expatriate managers, so as to further guarantee better job behavior and performance.

The propositions of our research provide a new angle of vision to view the relationship between expatriate managers' different job characteristic, task design and their working incentives, and it produces significant theoretical and practical implications. Theoretically, it contributes worthy knowledge to the field of expatriate managers' human resource management. Practically, for highly positioned staff in multinational corporations, the discussions of the study may help in their research by selecting, training and developing more comprehensive qualified expatriate managers to facilitate their work; for individual expatriate manager, they may benefit from knowing the function of incentive mechanism, so as to present better job behavior and performance through targeted and specific training, and to be more competent and qualified for the job.

\section{ACKNOWLEDGMENT}

Funding for this research was provided by National Natural Science Foundation of China under grants 71762033. The facilitation from international collaborative program and cooperation with Charles Sturt University in Australia is gratefully acknowledged. The assistance of Professor Mark Frost and Antony Bush and comments from an associate editor and two anonymous reviewers are also acknowledged.

\section{REFERENCES}

[1] Hackman J R, Oldham G R, "Motivation Through the Design of Work: Test of a Theory," Organizational Behavior and Human Performance, vol. 16, 1976, pp. 250-279.

[2] Robbins, Stephen P, and P. L. Hunsaker, "Training in Interpersonal Skills: Pearson New International Edition: TIPS for Managing People at Work, 6/E," Pearson Schweiz Ag, 2008.

[3] Lawler, Edward E., and J. R. Hackman, "Corporate Profits and Employee Satisfaction: Must They Be in Conflict?" California Management Review, vol. 14, 1971, pp. 46-55.

[4] Hackman, J. Richard, et al, “A New Strategy for Job Enrichment," California Management Review, vol. 17, 1975, pp. 57-71.

[5] Belout, Adnane, and C. Gauvreau, "Factors Influencing Project Success: The Impact of Human Resource Management," International Journal of Project Management, vol. 22, 2004, pp. 1-11.

[6] Eskerod, P., and B. S. Blichfeldt, “Managing Team Entrees and Withdrawals during the Project Life Cycle," International Journal of Project Management, vol. 23, 2005, pp.495-503.

[7] Zwikael, Ofer, and E. Unger-Avira, "HRM in Project Groups: The Effect of Project Duration on Team Development Effectiveness," International Journal of Project Management, vol. 28, 2010, pp. 413-421.

[8] Bakker, A. B., Demerouti, E.,\&Verbeke, W., "Using the Job Demandsresources Model to Predict Burnout and Performance," Human Resource Management, vol. 43, 2004, pp. 83-104.

[9] Wan L, “The Quality which Should Be Possessed by the expatriate manager of the State-owned Enterprise," Management Observer, vol. 21, 2014, pp. 101-102.

[10] Wu L., Zhang D., Wu X.C., "The Impact of Job Characteristics on Workers-Requirements-Control Models are Compared to Job Requirements-Resource Models," Progress in Psychological Science, vol. 2, 2010, pp. 348-355.

[11] Sun C.L., "The expatriate manager Authorization is Based on the Common Broker Framework,” Building Economy, vol.6, 2012, pp. 2934.

[12] Cao S.S., Yang G., "KPI Based Project Team Performance Review Discussion,” Modern Business Trade Industry, vol. 11, 2010, pp. 167.

[13] Zhang F.F., "Explore Ways to Improve Employee Creativity Based on the Work Feature Model," Market Modernization, vol. 14, 2014, pp. 104-105.

[14] Guo Y.L. (2002) . The incentive utility analysis of knowledge workers [J]. Modern finance and economics, (11):63-66

[15] Custer E., Rosenzweig E., “Organization and Management: System Approach and Contingency Approach,” Chinese Social Sciences Press, 2000 .

[16] Zhang Y.C., Liu P., Yin J.H., Deng X.J., "Working Characteristics Model: A Survey Based on Chinese Samples," Economic Science, vol. 4, 2005, pp. 117-126.

[17] Dixit A., "Incentives and Organizations in the Public Sector: An Interpretative Review,” Journal of Human Resources, vol. 37, 2002, pp 697-727.

[18] Maslow, A. H., "Motivation and Personality," Quarterly Review of Biology, vol. 1, 1970, pp. 187-202.

[19] Schneider, Benjamin, and C. P. Alderfer, "Three Studies of Measures of Need Satisfaction in Organizations," Administrative Science Quarterly, vol. 18, 1973, pp. 489-505.

[20] Xu N., Xu X.Y., “The Duality and Dynamic Ability of Technology Innovation, Based on the Empirical Analysis of High-Tech Companies," Chinese Industrial Economy, vol. 10, 2012, pp. 101-111.

[21] Liu Y.W., Hu Z.Y., "Flexible Incentive Mechanism Design and its Model Research,” vol. 24, 2010, pp. 43-46. 